\title{
Relational and Instrumental Perspectives on Compliance with the Law among People Experiencing Homelessness
}

Arabella Kyprianides, Department of Security and Crime Science, University College London, UK Ben Bradford, Department of Security and Crime Science, University College London, UK Jonathan Jackson, Department of Methodology, LSE, UK; University of Sydney Law School, Australia Clifford Stott, School of Psychology, Keele University, UK

Krisztián Pósch, Department of Security and Crime Science, University College London, UK

\section{Author Note}

Arabella Kyprianides, OCID id: 0000-0001-7168-089X, Department of Security and Crime Science, University College London, UK

Ben Bradford, OCID id: 0000-0001-5480-5638, Department of Security and Crime Science, University College London, UK

Jonathan Jackson, OCID id: 0000-0003-2426-2219, Department of Methodology, LSE, UK; University of Sydney Law School, Australia

Clifford Stott, OCID id: 0000-0001-5399-3294, School of Psychology, Keele University, UK

Krisztian Posch, OCID id: 0000-0001-7524-7049, Department of Security and Crime Science, University College London, UK

This work was supported by the Economic and Social Research Council [Grant \# ES/R011397/1]. The authors declare that there are no conflicts of interest. All study materials have been uploaded to a secure OSF site: https://osf.io/vbnhg/?view_only=95509ad0bb5b40d1af81952d803939ba

Correspondence concerning this article should be addressed to Arabella Kyprianides, UCL Department of Security and Crime Science, Shropshire House, 11-20 Capper Street, London WC1E 6JA, a.kyprianides@ucl.ac.uk. 


\begin{abstract}
Objective: We conducted an exploratory study testing procedural justice theory with a novel population. We assessed the extent to which police procedural justice, effectiveness, legitimacy, and perceived risk of sanction predict compliance with the law among people experiencing homelessness.

Hypotheses: We did not develop formal a priori hypotheses but examined five general research questions. (1) Are there positive associations between police procedural justice, police legitimacy, and compliance? (2) Do procedural justice and legitimacy differentially predict compliance depending on the particular type of offending? (3) Are there positive associations between police effectiveness, perceived risk of sanction and compliance? (4) Does the perceived risk of sanction differentially predict compliance depending on the particular type of offending? (5) Are there positive associations between moral judgements about the different offending behaviors and compliance?
\end{abstract}

Method: Two-hundred people (87\% male, 49\% aged between 45-64, 37\% white British) experiencing homelessness on the streets of an inner London borough completed a survey that included measures of procedural justice, police legitimacy, perceived risk of sanction, morality, and compliance.

Results: (1 \& 2) Procedural justice and police legitimacy were only weakly (and not significantly) associated with any of the three types of compliance (compliance with low-level crimes, behaviors specific to the street population, and high-level crimes). (3 \& 4) Police effectiveness positively predicted compliance via perceived risk of sanction, but only for the kind of street population specific offenses that can be important for survival on the streets such as begging and sleeping in certain localities. (5) Morality was positively associated with all three types of compliance behaviors. Supplementary analyses suggested a small amount of instability in the results however, possibly because of the relatively small sample size.

Conclusions: The lack of relevant relational connections to legal authority may explain why procedural fairness and perceptions of police legitimacy were not particularly important predictors of compliance in this context. More research is needed into the types of marginalized communities for whom structural factors of alienation and lack of access to resources may serve to reduce normative group connections. Future work should test whether the need to survive on the streets leads people to discount some social and relational constraints to behavior, making people (almost by definition) more instrumental in relation to law and law enforcement.

Key words: procedural justice; perceived risk of sanction; compliance; police; homeless people

\title{
Public Significance Statement
}

Relational concerns might not be related to compliance in the homeless street population context because breaking the law is critical to survival on the street and this may weaken identification with the group that the police represents. Deterrence-based policing strategies may discourage behaviors specific to the street population (e.g., begging on the streets and sleeping rough in restricted areas). However, deterrence-based policing strategies might not be associated with the 'wider' criminal activity of this same group - activity in which some of them were engaged. 


\section{Relational and Instrumental Perspectives on Compliance with the Law among People Experiencing Homelessness}

People obey the law for a variety of different reasons, but the two we focus on in this article are fair treatment at the hands of police officers (promoting perceptions of police as legitimate enforcers of the law, Tyler, 2006) and deterrent behavior from the police (stimulating the fear of the consequences of breaking the law, Nagin, 2013). A central distinction in police practice, policy and, indeed, ideology rests on which one of these motivations police-centric efforts should prioritize to reduce offending consent-based, legitimacy-building policies that promote normative compliance with the law (relational perspective) or enforcement-led approaches that concentrate on the provision of a credible deterrent threat (instrumental perspective)?

We consider these relational and instrumental perspectives on compliance in a context where noncompliance is common: namely, people living on the streets of London (Pyper et al., 2019). How might the police motivate compliance among this highly marginalized group? Procedural justice theory (Tyler, 1990, 2006) predicts that procedural justice and legitimacy are more important than instrumental factors, so long as individuals identify with the group that an authority represents (Tyler \& Lind, 1992; Tyler, 1997; Lind \& Tyler, 1998). But how does this play out in this exploratory study of a marginalized population who sometimes have to commit crimes to survive and who have generally high levels of alienation from society? Might the police be able to generate compliance by acting in a procedurally just and legitimate manner, by demonstrating the risk of sanction, or some combination of the two?

Answers to these questions are important for at least three reasons. The first relates to the notion of shared group identity that sits at the heart of procedural justice theory (Tyler, 1990, 2006). When police officers represent a social group that is salient and important to those they encounter, procedural justice is especially meaningful. Fair treatment at the hands of police officers indicates inclusion, belonging, and status within the group, and the strengthening of group bonds and a consequent desire to act in accordance with group norms motivates compliance. But what about a group so marginal to mainstream society that they find themselves living on the streets, among whom processes of social identification and belonging may have broken down or been fundamentally re-aligned, and who may have very immediate and pressing reasons to offend? This group might, as a result, be less attuned to the relational and value-relevant aspects of procedural justice and consequently, procedural justice and/or legitimacy might have few associations with compliance amongst this group. Instrumental factors may be more important in such a context (Lind \& Tyler, 1998; Tyler \& Lind, 1992).

Second, examining the relative weight of legitimacy versus deterrence-based predictors of compliance among this special population tests the generalizability of procedural justice theory to a vulnerable group that sometimes needs to commit crimes to survive. Numerous studies have identified associations between legitimacy judgments and people's compliance behavior (Walters \& Bolger 2019), while finding that deterrence-related factors tend to be much less relevant. However, a large majority of these studies have sampled the general population, youth, or students, with most of the rest focusing on prisoners (for exceptions see Walters \& Morgan 2018; White et al. 2016). Arguably, none have focused on a non-prison based population as marginal and socially excluded as the homeless. It may simply be that people experiencing homeless feel that they need, on occasions, to commit crime to survive. This may, in turn, further weaken their identification with the group that the police represent.

Third, people living on the streets have high levels of contact with police. They are often vulnerable in multiple ways, prone to high levels of substance misuse as well as other physical and mental health problems. They can be forced to commit offenses just to survive. Developing ways to police this population that are attuned to these issues is vital if police activity is not to exacerbate and embed their vulnerability and marginality. Deterrence-based strategies seem likely to do exactly this (Geller et al. 2014; Trinkner et al. 2018), as well as providing a direct route into the criminal justice system, with all its attendant potential harms (McAra \& McVie, 2007). Knowing whether the provision of a credible deterrent threat has any value in this context is central to developing appropriate police tactics and strategies.

For various reasons - perhaps most importantly the focus on general population samples of most research in this area-relational perspectives of compliance have dominated procedural justice theory research in contexts like the United States, United Kingdom, and Australia. Researchers have rarely tested instrumental motivations among marginalized groups at the empirical level. Indeed, some have argued that there has been a lack of adequate attention given to the social and cultural context 
within which the framework operates, and that more research is needed on groups and types of people who have the most contact with the police (Nagin \& Telep, 2017; Tankebe, 2009).

Original conceptualizations of procedural justice theory (Lind \& Tyler, 1988; Tyler \& Lind, 1992; Tyler, 1997) incorporated both relational and instrumental motivations for compliance, and more recent work has also discussed the interplay between relational and instrumental motivation within procedural justice theory (Reisig et al., 2020; Trinkner, 2019; Jackson et al., 2021). On this account, which type of motivation is most important depends on dynamics of the authority-subordinate relationship and the context of a given situation. When individuals do not identify with the group an authority represents, or have little motivation to be a member of that group, procedural justice theory predicts that instrumental factors will drive orientations toward that authority, judgments/perceptions of it, and compliance/cooperation behavior to a greater extent than relational factors (Tyler, 1997). Applied to the current context, it may be that the need to survive makes people discount relational constraints and bonds. The importance of procedural justice concerns may also be different among the population studied here for reasons related to uncertainty and social status. For example, it is possible that their low status is so clear to people experiencing homelessness that there is no uncertainty that directs their attention to procedural justice concerns (cf. Lind \& Van Den Bos, 2002). Conversely, the quality of interpersonal treatment and decision-making might be important because it communicates inter- rather than intra-group standing (cf. Heuer \& Stroessner, 2011).

In the current study, we investigated whether the tenets of procedural justice theory apply to one particular community that often features in these kinds of debates: people experiencing homelessness. We begin by outlining how authorities police homeless people in London and provide a review of the literature on police-centered predictors of compliance. We then review the methods and findings. We conclude with the idea that the answer to issues of crime and offending associated with homelessness is unlikely to be policing in its traditional forms, but that if policing is going to work, it needs to be more innovative and involve other services working in coordination with police. Currently there are significant debates within and around policing centered on the Black Lives Matter movement and the notion of 'defunding' the police. Important protagonists within these debates are critical of procedural justice theory (e.g., MacCoun, 2005; Vitale, 2018), seeing the potential for its cynical use to provide a smokescreen to cover the raw and discriminatory power of police. The argument is that "false consciousness" could plausibly occur when authorities use the appearance of a fair procedure as a way to co-opt people by distracting them from objectively unfair outcomes they receive (MacCoun, 2005). More relevant perhaps to the current article is an apparently growing recognition that police cannot provide long-term solutions to the problems faced by those with whom they have frequent contact, such as people living on the streets. Indeed, our findings suggest police may be unable to address even proximate questions about the high level of offending within this group (Kyprianides et al., 2020).

\section{Policing the Homeless}

Society marginalizes people experiencing homelessness in many ways: they experience not only personal and economic hardship, but also stigma and structural discrimination because of their uncertain housing status and the forms of deep social exclusion that interact with homelessness, such as histories of institutional care, substance misuse, and participation in street culture activities (an experience termed 'multiple exclusion homelessness'; Fitzpatrick et al., 2011). Much research in the UK and elsewhere has documented the instrumental consequences of such exclusion, with multiple exclusion homelessness affecting people's ability to transition out of homelessness and into employment and stable housing, as well as their well-being (Fitzpatrick et al., 2011).

Increasingly, a punitive approach has defined the policing of homelessness in the UK (Cooper, 2016; also US, Robinson, 2019). Rough sleeping has often been at the forefront of the political agenda, and there has been an increase in the use of enforcement measures in English public policy. Nineteenthcentury vagrancy laws are still in effect in the UK, making it illegal to sleep rough or beg, and they are now coupled with zero-tolerance enforcement strategies that target street-level activities - most of them associated with homelessness (Cooper, 2016). A number of recent studies, however, complicate the narrative of homelessness policing as uniformly hostile, punitive, and exclusionary; instead, they reveal a pattern of simultaneous disciplinary and less punitive approaches that promote joint police-social service interventions in London and other cities around the world (Stuart, 2015). Multi-agency initiatives bringing together a range of stakeholders are now common. This includes police, outreach 
services, local homelessness organizations, local councils and others, who work together to tackle issues such as begging, rough sleeping, criminal activities, and anti-social behavior (Sanders \& Albanese, 2017). People living on the streets are therefore often subject to two contrasting modes of social control: one enforcement led, the other concerned with relationship building and consensual movement towards less risky lifestyles. Indeed, there exists a large body of work detailing how homelessness has been criminalized and managed via systems that vicariously control, care, observe and/ or punish (Feldman, 2004; Quirouette, 2018).

\section{What Can Police Do to Motivate Compliance: Procedural Fairness or Deterrence?}

Procedural justice theory has significantly contributed to our understanding of why people comply with the law. The theory speaks to four key principles that police officers can adopt in their dealings with members of the public if they are to encourage willing compliance. Police officers should treat people with fairness, dignity and respect; be transparent and trustworthy in their actions; provide the opportunity for voice; and be impartial in their decision making. When police adopt and enact these pillars of procedural justice, people are more likely to perceive the police to be legitimate (i.e., they view the police as a morally appropriate authority that is entitled to be obeyed) (Jackson, 2018; Tyler, 1990). In turn observational research consistently shows that public perceptions of police legitimacy predict behavioral intentions to comply with the law, over and above beliefs about risk of sanction such as getting fined or arrested (Murphy, Bradford, \& Jackson, 2016). This appears be the case for the general public in many different countries, such as the US (Sunshine \& Tyler, 2003), the UK (Jackson et al. 2012), Australia (Mazerolle, Antrobus, Bennett, \& Tyler, 2013) and Slovenia (Reisig Tankabe \& Mesko, 2014), and for both general criminal behaviors (Sunshine \& Tyler, 2003), as well as for specific offenses such as breaking traffic laws (Bradford, Hohl, Jackson, \& MacQueen, 2015) and for offender populations including domestic violence perpetrators (Paternoster et al. 1997), violent offenders (Papachristos, Meares \& Fagan, 2012), and adolescent offenders (Gau \& Brunson, 2010; Piquero et al., 2005).

Procedural justice and legitimacy are usually positioned as factors predicting compliance with the law in contrast to a deterrence-based or instrumental perspective, in which individuals are rational actors motivated to comply out of the fear of the consequences should they be detected breaking the law (Allingham \& Sandmo, 1972; Gibbs, 1968; Tittle, 1969). If the benefits of breaking the law outweigh the costs, then the rational choice will be non-compliance; conversely, if the costs of breaking the law outweigh the benefits then the rational choice will be compliance. Three factors play a role in this decision-making process: (1) the risk of detection of non-compliance, (2) the effectiveness of authorities in dealing with non-compliance (particularly the speed with which sanctions are delivered), and (3) the severity of sanction associated with non-compliance (Becker, 1968). If risk of detection, authority effectiveness, and sanction severity are high then non-compliance is the risky choice and compliance is rational. According to the instrumental perspective, would-be offenders will abstain from offending if they perceive the possibility of getting caught and punished by the authorities to be high (Williams \& Hawkins, 1986).

Some research has observed a link between police effectiveness, risk of sanction, and compliance (Andreoni, Erard, \& Feinstein, 1998; Nagin, 2013). Overall, however, the evidence for general deterrence is weak at best (Pratt et al., 2006). By contrast, focused deterrence strategies, such as those targeting gang and group-involved drug markets, overt drug markets, or repeat offenders, do appear to have a significant, albeit small, effect on crime (Braga et al., 2018). Though it seems most people are not accurate rational choice calculators when it comes to decisions about offending, some individuals, in some places, at some times can be deterred from offending by police activity.

This latter distinction is relevant to the present study because, in the regulatory context of street population activities in the UK, the probability of being caught and punished for violating laws is high (Crisis, 2018). The increasingly punitive approach to policing homelessness in the UK in recent years has entailed multi-agency initiatives targeting people experiencing homelessness (Cooper, 2016; Sanders \& Albanese, 2017). At the most practical level, many offenses committed by people experiencing homelessness are highly visible, occurring in public places, and often directly engaging with passersby (e.g., begging, consumption of illegal drugs). People living on the street are also subject to high levels of police surveillance. For example, officers in London and elsewhere undertake highvisibility patrols in homeless 'hot spots' targeting their resources and activities to those places where 
homeless crime is most concentrated (Crisis, 2018). Focusing policing activity in hot spots aims to prevent homeless criminal behaviors in these specific areas, as well as to have a wider effect on the behavior of those subject to them. Such efforts are part of an attempt to get people experiencing homelessness 'off the streets' via policing. It is therefore likely that people experiencing homelessness are detected and sanctioned for offenses relatively frequently, and also see others being detected and sanctioned frequently. Considering that risk perceptions can be influenced by personal experience (Anwar \& Loughran, 2011; Paternoster \& Piquero, 1995), these experiences may influence individuals' behaviors - in a sense, people living on the streets are more or less continuously the target of focused police attention.

By contrast, there are good reasons for suspecting that procedural justice and legitimacy will be less important predictors of compliance among this group - perhaps the most obvious one being their socio-structural location. A recent ethnographic study of policing the street population in an inner London borough found that, while fairness was clearly important to people experiencing homelessness in their interactions with the police in an abstract sense (i.e., it was pleasant to be treated with respect by everyone in general), instrumental outcomes mattered most during their interactions with officers (Kyprianides et al., 2020). Procedural fairness was less important because there were overarching instrumental outcomes at stake, which affected their very survival potential, and these took precedence. In many cases people experiencing homelessness are offending to survive (Batty \& Reeve, 2011; MOJ, 2010). As such, a central claim based on procedural justice theory-legitimacy encourages behavior in line with that mandated by authorities, as obedience becomes a value in itself - may not apply in this context.

Procedural justice theory also predicts that instrumental factors will be more important among people who do not care about being, or do not feel they are, a member of the group the police represent (Lind \& Tyler, 1988; Tyler \& Lind, 1992); it is people who identify with the group the authority represents who will be more concerned about their treatment by officers as group authorities (Tyler, 1997). Building on this, we anticipated that members of the street population in our sample would less attuned to the relational and value-relevant aspects of police activity, so we predicted that the wellestablished procedural justice $\rightarrow$ legitimacy $\rightarrow$ compliance pathway would not work in the same way for this highly marginalized group as it would for the general population. Of course, even if that were the case, it continues to be important that police officers treat people experiencing homelessness with respect and dignity. They should do so because it is the humane thing to do, and not simply because it might help to reduce crime (cf. Nagin \& Telep, 2020).

\section{Additional Motivations for Compliance}

Legitimacy and deterrence are not the only factors shaping compliance with the law, even if these are the primary levers in the hands of the police. A host of other factors are likely to be involved, including peer effects, social learning, self-control, habit, and normative pressures (Bottoms, 2013). We focus on one particularly important factor that is thought to mediate others-moral judgments about the behaviors concerned. Put simply, most people comply with most laws, most of the time, because they tend to think the behaviors proscribed by law are wrong (Antonaccio \& Tittle 2008; Messner 2012; Wikström, 2012). Such moral judgments are shaped by their upbringings, social contexts, group memberships and personalities (Svensson et al., 2016). In addition, the law has the power to define things as non-normative and/or wrong, particularly in relation to less serious behaviors, such that it becomes immoral or at least socially unacceptable to do things that are against the law (McAdams, 2017).

In the current context, the way people think about criminal behavior may vary significantly according to the nature of the behavior concerned. This, coupled with the practical reason that members of the street population sometimes feel that they must offend to survive, means that it does not make sense to think about crime as a singular act that a person can be deterred from undertaking in some general sense (Nagin, 2013) or about which they form some overall moral judgment. Different kinds of criminal behavior may be differentially shaped by police activity, people's reactions to that behavior, and their moral judgments about it (Bouffard et al. 2018). For example, given that street population 'nuisance' behavior is continuously the target of focused police attention, individuals experiencing homelessness are likely to have a relatively good sense of their chances of being caught if they engage in such behavior, a perspective they may lack for other types of offending. Relatedly, police legitimacy 
might motivate disengagement from some types of offending like low level offenses that people tend not to see as morally wrong, but not others like higher level offenses that are more closely associated with widely held moral values and norms. In other words, legitimacy may be more predictive of compliance with laws that cover morally grey areas, such as the use of soft drugs, than laws that cover behaviors very widely accepted as wrong, such as burglary or assault (cf. Tyler, 1990). Indeed, existing work has found that procedural justice concerns are less strongly emphasized when moral mandates are in play (Skitka \& Houston, 2001).

\section{Overview of Research Questions and Current Study}

We distilled the previous discussion into five essential questions relevant to street populations. First, what are the links between police procedural justice, police legitimacy, and compliance? Second, does police procedural justice play a different role depending on the particular type of offending? Third, what are the links between police effectiveness, perceived risk of sanction and compliance? Fourth, does the perceived risk of sanction play a different role depending on the particular type of offending? Fifth, what are the links between moral judgements about the behaviors concerned and compliance with those behaviors?

In the present study, we sought to answer these questions by examining how relational (procedural justice and police legitimacy) and instrumental (police effectiveness and risk of sanction) concerns predicted the street population's decisions to comply with the law. We studied three different types of offending: low-level offenses (e.g., shop lifting), a range of offenses specific to the street population (e.g., begging), and higher-level offenses (e.g. robbery).

\section{Participants}

\section{Method}

This study was part of a broader ethnographic project that examined interactions between police and homeless people in London by shadowing policing patrols and observing the homeless community (Kyprianides et al., 2020). The first author established access, rapport, and trust with research participants during that project (May - October, 2019) prior to survey distribution (February and March, 2020). This then allowed the first author to recruit people experiencing homelessness on the streets of an inner London borough $(N=200)$ solely on the basis of their willingness to participate. We based our desired sample size on recommendations for using structural equation modeling (SEM) to analyze models of average complexity (Kline, 2011) and more recent simulation studies using SEM models of similar complexity to those we report in this paper (Sideridis et al. 2014; Wolf et al. 2013).

Eighty-seven percent of participants were men, 49\% were aged between 45-64 (48\% 25-44, $3 \% 18-24,1 \% 65+$ ), $37 \%$ were white British (33\% white other, $14 \%$ black or black British, $8 \%$ mixed background, $6 \%$ other ethnic group, 3\% Asian or Asian British). Fifty-seven percent were born in the UK, and 54\% had lived in the UK all their life (34\% 5-10 years, $12 \% 2-5$ years, $1 \% 1-2$ years). The sample was roughly representative of people rough sleeping in England (86\% male, 54\% aged 36-55, $60 \%$ white, $64 \%$ UK nationals; MOJ, 2019). We are confident that most, if not all, participants actually lived on the streets at the time of data collection because they were recruited at soup kitchens that specifically targeted people living on the streets, most participants carried around evidence that they were rough sleeping (e.g., sleeping bags and blankets), and all participants reported that they were rough sleeping - 52\% had been rough sleeping for 6 months-1 year, 22\% 1-2 years, 15\% 1-3 months, $11 \% 3$ 6 months, $1 \%$ less than a month and $1 \%$ more than 2 years.

Participants reported relatively high levels of offending across all three groups of compliance types: compliance with low-level crimes, compliance with behaviors specific to the street population, and compliance with high-level crimes (see Table 1). Although engagement in high-level criminal activities was lower than engagement in low-level and street population specific activities (where only in relation to vandalism and shop lifting did a majority report not offending), approximately $40 \%$ of our sample self-reported engagement in at least one of the higher-level criminal activities such as burglary and robbery. This is a large percentage given the seriousness of the behaviors concerned. It is also worth reiterating that the street population has extensive experience of policing: their estimate of policing outcomes (e.g., risk of sanction) might be arguably be more accurate than most members of the public, at least in relation to certain crime types. 


\section{Outcome and Predictor Variables}

Participants read and completed a questionnaire that included items assessing perceptions of the police in London, compliance behaviors, morality associated with these behaviors, and risk of getting caught and punished by the police for engaging in those behaviors. All items used a $1=$ Strongly Disagree, 2 $=$ Disagree, $3=$ Neither Agree nor Disagree, $4=$ Agree, $5=$ Strongly Agree Likert scale unless otherwise indicated. See the Appendix for full item wordings and the following link for the complete study materials: https://osf.io/vbnhg/?view only=95509ad0bb5b40d1af81952d803939ba

We measured police procedural justice using three items (e.g., "The police treat people with respect" (Jackson \& Bradford, 2019). We measured perceived police legitimacy using two distinct, albeit overlapping, constructs: duty to obey (three items, e.g., "I feel a moral obligation to obey the police" and normative alignment (three items, e.g., "I support the way the police usually act)" (Trinkner, Jackson, \& Tyler, 2018).

We included two measures of police effectiveness. We measured general police effectiveness using three items (e.g., "The police are effective at providing a visible patrolling presence") (Jackson, Bradford, \& Stanko, 2012) and police effectiveness specific to street population behaviors using three additional items (e.g. "The police are good at moving people on and stopping them from begging") that we designed.

We measured three levels of compliance: compliance with low-level crimes, compliance with behaviors specific to the street population, and compliance with high-level crimes. We selected these behaviors based on discussions with people living on the streets of the same London borough about how they viewed different types of offending; most notably, the types of offenses they viewed as necessary for survival. We asked participants to indicate on a scale $1=$ Often, $2=$ Sometimes, $3=$ Rarely, $4=$ Never whether they had, in the past year, committed low-level offenses (e.g., "Taken something from a shop without paying for it" (Trinkner, Jackson \& Tyler 2018), offenses specific to the street population (e.g., begged on the street or elsewhere), or high-level offenses (e.g., robbery).

Participants rated the morality and perceived risk of sanction (using items developed by Jackson and colleagues (2018)) for each of the compliance behaviors. We measured morality by asking participants to rate 'how wrong' they judged the compliance behaviors to be on a scale $1=$ Not wrong at all, 2 = Not too wrong, 3 = Somewhat wrong, $4=$ Very wrong. We measured perceived risk of sanction by asking participants to rate 'how likely it is that you would be caught and punished' for those same behaviors on a scale $1=$ Not at all likely, $2=$ Not very likely, $3=$ Fairly likely, $4=$ Very likely.

\section{Procedure}

The ethical review board at University College London (UCL; 15985/001) approved the research. The first author collected data between February and March 2020 at outdoor places where food was served to people experiencing homelessness across the inner London borough. Participants provided informed consent (verbal consent protocols were followed where participants had poor literacy skills and the lead author assisted with completing the questionnaire). The questionnaire booklet took approximately 10 minutes to complete. Participants received $£ 5$ (roughly \$7 US dollars) compensation for their time. The first author was present throughout the entire process and provided help or support as required. Given the rate at which participants disclosed illegal activity, we do not believe this had any biasing effects, and it meant that clarification could be offered when necessary.

\section{Analysis Plan}

\section{Results}

We tested three separate models of compliance using compliance with low-level crimes, compliance with behaviors specific to the street population, and compliance with high-level crimes as the respective outcome variables. In each of the three compliance models, we included only the relevant morality and perceived risk of sanction items (i.e., those items relating to compliance with low-level, street population, and high level crime, respectively). In order to validate our measures, we first tested the factorial structure of the latent variables by specifying a measurement model using confirmatory factor analysis (CFA) in MPlus 8 (setting the indicators to be ordinal) for each model. Next we investigated the relations between these variables using structural equation modeling (SEM) to estimate regression paths between latent constructs in MPlus 8. For each type of compliance behavior, we tested (a) the relationship between latent constructs police procedural justice, police legitimacy, compliance; and (b) 
the relationship between latent constructs police effectiveness, perceived risk of sanction, and compliance. Although the existing literature would support additional paths in the SEM model, given our small sample size and particular aims of the study, we opted for a simpler and more parsimonious model. For example, studies have suggested that police effectiveness also predicts police legitimacy in situations where the sample does not identify with the group the police represent (Lee \& Cho, 2020). Researchers have argued that procedural justice serves a binding function where it promotes the internalization of group norms (Lind \& Tyler, 1988; Tyler \& Blader, 2003).

To additional possible concerns regarding statistical power given our sample size, we also (a) fitted the same models without specifying any indirect effects, (b) fitted ordinal regression models on each of the individual compliance items using SPSS, and (c) conducted a Bayesian analysis that included a sensitivity analysis. Across all specifications, the key pattern of results remained the same, aside from a certain low-level instability regarding the role of legitimacy predicting street-specific compliance and high-level compliance (see Supplemental Materials for analyses). We also conducted sensitivity analyses controlling for key socio-demographic subject characteristics. We ran the same model whereby all latent variables in the model were also regressed on gender, age, ethnicity, and country of birth. The results remained the same, albeit here the low-level instability related to legitimacy predicting high-level compliance(see Supplemental Materials for analyses). We report the simple model without controls given our relatively small sample size.

\section{Descriptive Statistics}

Descriptive statistics and correlations of the key measures appear in Table 2. Key variables were correlated with the three different compliance types, but the strength of the associations differed (e.g., procedural justice with compliance with low-level crimes $(r=.41)$, compliance with behaviors specific to the street population $(r=.24)$, and compliance with high level crimes $(r=.54))$.

\section{CFA Measurement Models}

We tested three separate measurement models, one for each of the types of compliance, and all three models fit the data well (where one typically looks for CFI >.95; TLI >.95; RMSEA <.08 - see Hu \& Bentler, 1999).

The low-level compliance model that included six covarying latent constructs of police procedural justice, police legitimacy, police general effectiveness, perceived risk of sanction, morality, and compliance with low-level crimes produced adequate fit indices (Chi-Square $=413.46 \mathrm{df}=309, p$ $=<.001$; RMSEA $=.06[.04, .07]$; CFI $=.99$; TLI $=.99$ ), with all standardized factor loadings $>.8$. Although differences were negligible comparing the approximate fit statistics between measurement models that combined normative alignment and duty to obey into one 'legitimacy' latent construct, and models that differentiated normative alignment and duty to obey as two separate constructs, we opted for the one latent construct of legitimacy for a simpler analytical model (in both cases, overall results remained the same, see Supplemental Materials for analyses).

The street population compliance model that included six covarying latent constructs of police procedural justice, police legitimacy, police street population specific effectiveness, perceived risk of sanction, morality, and compliance with behaviors specific to the street population produced adequate fit indices (Chi-Square $=436.33, \mathrm{df}=309, p=<.001$; RMSEA $=.06[.05, .08]$; CFI $=.99$; TLI $=.98)$, with all standardized factor loadings $>.8$.

The high-level compliance model that included six covarying latent constructs of police procedural justice, police legitimacy, police general effectiveness, perceived risk of sanction, morality, and compliance with high-level crimes produced adequate fit indices (Chi-Square $=401.01, \mathrm{df}=284$, $p=<.001$; RMSEA $=.06[.05, .08] ; \mathrm{CFI}=.99$; TLI $=.99)$, with all standardized factor loadings $>.8$ (after dropping the fifth perceived risk of sanction item that proved to be problematic in this model with a standardized factor loading $<.5$ ).

We use these three models as the basis for answering our questions using structural equation modelling (SEM). Note that we also tested a CFA model that included all three types of compliance, alongside the other constructs. This model provided an excellent fit to the data (Chi-Square $=1884.833$, $\mathrm{df}=1574, p=<.001$; RMSEA $=.04[.04, .05]$; CFI $=.99$; TLI $=.98)$ with all standardized factor loadings $>.8$. 


\section{Answering our Research Questions: Structural Equation Modeling}

We sought to answer our research questions by specifying three structural models - one for each type of compliance - that investigated direct and indirect pathways from (a) police procedural justice to legitimacy to compliance, and (b) police effectiveness to perceived risk of sanction to compliance (see Figure 1). We estimated indirect effects using the INDIRECT command within MPlus, which estimates indirect effects with delta method standard errors (Muthen, 2011). The models included police procedural justice and police effectiveness as exogenous predictor variables, legitimacy and perceived risk of sanction as the mediating variables, and compliance as the outcome variable. We included morality as a covariate in the model (i.e., including it as an additional exogenous predictor of compliance and allowing it to covary with the constructs that are not compliance). Note that in the lowlevel compliance, street population compliance, and high-level compliance models, we entered each type of compliance as the 'compliance' latent construct respectively; and police effectiveness was entered as the 'police effectiveness' latent construct for the low-level and high-level compliance models; and street population police effectiveness was entered as the 'police effectiveness' latent construct for the street population compliance model.

We present standardized regression coefficients for all paths in Table 3. The low-level compliance model (Chi-Square $=486.969, \mathrm{df}=314, p=<.001$; RMSEA $=.07[.06, .09]$; CFI $=.98$; $\mathrm{TLI}=.98)$ explained $67 \%$ of the variance in compliance with low-level crimes $\left(\mathrm{R}^{2}=.67\right), 63 \%$ of the variance in police legitimacy $\left(\mathrm{R}^{2}=.63\right)$, and $15 \%$ of the variance in low-level crime perceived risk of sanction $\left(\mathrm{R}^{2}=.15\right)$. The street population compliance model $($ Chi-Square $=438.361, \mathrm{df}=314, p=<$ $.001 ; \mathrm{RMSEA}=.06[.05, .08]$; CFI $=.99$; TLI $=.99)$ explained $47 \%$ of the variance in compliance with beahaviors specific to the street population $\left(\mathrm{R}^{2}=.47\right), 62 \%$ of the variance in police legitimacy $\left(\mathrm{R}^{2}=\right.$ $.62)$, and $15 \%$ of the variance in street population crime perceived risk of sanction $\left(\mathrm{R}^{2}=.15\right)$.

The high-level compliance model (Chi-Square $=367.499, \mathrm{df}=289, p=<.001 ; \mathrm{RMSEA}=.05$ $[.03, .07]$; CFI $=.99$; TLI $=.99)$ explained $76 \%$ of the variance in compliance with high-level crimes $\left(\mathrm{R}^{2}=.76\right), 63 \%$ of the variance in police legitimacy $\left(\mathrm{R}^{2}=.63\right)$, and $12 \%$ of the variance in high-level crime perceived risk of sanction $\left(\mathrm{R}^{2}=.12\right)$.

What are the links between police procedural justice, police legitimacy, and compliance; and does police procedural justice play a different role depending on the particular type of offending?

We first turn to whether the police were seen to act in procedurally fair ways and were therefore seen as legitimate, and whether procedural justice and/or legitimacy were associated with offending across the three different models. Although police procedural justice was positively associated with perceptions of police legitimacy in all cases, police procedural justice and perceptions of police legitimacy were only weak predictors (and not significantly significant) of the compliance behaviors. What are the links between police effectiveness, perceived risk of sanction and compliance; and does the perceived risk of sanction play a different role depending on the particular type of offending?

Second, were the police seen as generating a sense that they were effective and providing a credible risk of sanction, and if so, did the effect of risk of sanction vary in relation to the three different types of offending? Police effectiveness was a positive (and statistically significant) predictor of perceived risk of sanction in all three models, with very similar effect sizes. General police effectiveness and perceived risk of sanction for engaging in low-level and high-level crime (i.e., deterrence) were weak and insignificant predictors of compliance with low-level crimes nor compliance with high-level crimes, respectively. However, perceived risk of sanction for engaging in street population specific crime was a positive (and statistically significant) predictor of compliance with behaviors specific to the street population. Moreover, the direct effect of street population-specific police effectiveness on compliance with behaviors specific to the street population was weak and not statistically significant: the association between street population-specific police effectiveness and compliance was almost entirely mediated by perceived risk of sanction. In other words, self-reported compliance with behaviors specific to those living on the streets (e.g., drinking on the street, buying or using drugs such as spice or heroin) was higher when respondents perceived a relatively high risk of sanction which, in turn, was associated with the belief that the police were effective in policing people like them.

What are the links between moral judgements about the behaviors concerned and compliance with those behaviors?

Finally, morality was a strong (and statistically significant) predictor or all three types of compliance. In other words, compliance with the law was more likely when members of the street 
population felt a moral or ethical obligation or commitment: the more wrong they perceived behaviors to be, the greater their compliance.

\section{Discussion}

The present study investigated whether instrumental concerns about being caught and punished for noncompliance (a result of perceived police effectiveness) more strongly predicted homeless people's decision to comply with the law than relational concerns about fair treatment and police legitimacy. We found that they did, although only in one specific case: Police effectiveness positively predicted compliance via perceived risk of sanction, but only for the kind of street population specific offenses that can be important for survival on the streets such as begging and sleeping in certain localities. We also examined whether these processes varied in relation to three different types of compliance behaviors (compliance with low-level crimes, behaviors specific to the street population specific, and high-level crimes). We found that they did. Procedural fairness and perceptions of police legitimacy did not seem to be especially important in explaining a statistically significant amount of variation in any of the three types of compliance behaviors. However, perceptions of police effectiveness was a positive predictor of street population-specific compliance behaviors via perceived risk of sanction for those behaviors. Importantly, we also found that morality strongly predicted all three types of compliance behaviors, such that compliance with the law was reported when members of the street population felt a moral or ethical obligation or commitment: the more wrong participants perceived behaviors to be, the greater the self-reported compliance with those behaviors.

When it comes to offending by the street population, only deterrence-based theories of compliance seem to have value, and even then only in relation to particular aspects of the law. In this particular context, but also perhaps more widely, it is important to think about different types of offending when we talk about compliance, and to recognize that compliance behaviors may be differentially related to police behavior (and some not at all). People in different circumstances might have different interests in relation to different laws. Our findings suggest that self-reported compliance with behaviors specific to those living on the street is higher when members of the street population perceive a risk of sanction in relation to those specific offenses. By contrast, we did not observe an association between sanction risk and our other two measures of compliance - here, our results were much more similar to extant studies showing little or no association between perceived sanction risk and self-reported compliance.

There was no statistically significant association between the legitimacy of the police and respondents' self-reported compliance behavior (although supplementary analyses suggest a certain low-level instability to this finding, probably related to low statistical power-we return to this in the Limitations section). This stands in contrast to many other procedural justice theory studies of selfreported compliance, which generally do identify such a link (Walters \& Bolger 2019). One potential explanation for this may be that engagement in illegal activity for the sake of survival - where legitimacy effects are ruled out by necessity - has an accretive effect on those involved that weakens and even further breaks down the general association between perceived police legitimacy and compliance. That is, some members of the street population are forced to discount social and relational constraints on behavior because they need to commit some offenses to survive. Over time they learn to discount the behavior of authorities in a more general sense as well. Such a process would seem to be reflected in the hopelessness and alienation people experiencing homelessness often feel (cf. Fitzpatrick et al., 2011). Although not all people experiencing homelessness offend (see McCarthy, 2013), often some degree of criminal behavior is inevitable (Kyprianides et al., 2020; Batty \& Reeve, 2011; MOJ, 2010).

Returning to the initial theoretical motivation for this study, legitimacy is primarily construed as an intragroup phenomenon in procedural justice theory. Group authorities such as police can, by behaving in ways that generate legitimacy, motivate compliance with group norms and rules through processes of identification, moral engagement, and internalization. It may be that people experiencing homelessness are already estranged from the police and the group they represent. The need to survive may then further weaken constraints and bonds, so these processes simply break down, because they do not think of themselves as being group members or that police represent a social category they belong to. This explanation is consistent with the work by Lind and Tyler (Lind \& Tyler, 1988; Tyler \& Lind, 1992; Tyler, 1997) and recently discussed in Trinkner (2019), Reisig et al., (2020), and Jackson et al., 
(2021). Based on this account, people are less attuned to process and more interested in outcomes when they do not identify with the superordinate group that an authority represents.

Like many others, we would argue that it continues to be imperative for police officers to treat people experiencing homelessness with respect and dignity. They should do so because it is the humane thing to do, not simply because it might help reduce crime. They should also do so because homeless people's engagement with the police and the criminal justice system extends beyond a focus on compliance with the law (to willingness to report victimization for example; Bell, 2019); and police officers must afford homeless victims support when accessing police services.

Our findings also highlight the importance of morality in predicting law-abiding behavior. This was not confined to compliance behaviors specific to the street population specific, but included compliance with low-level and high-level crimes too. In other words, some of our participants agreed that certain offenses were wrong and told us they refrained from committing those offenses. Perhaps unsurprisingly, even in a situation as extreme as the one our respondents were experiencing, there appears to be a moral and ideological dimension to compliance that has little to do with police activity and enforcement of the law, at least in any direct sense. What we have not assessed is how people came to form these moral values in the first place. It would be a fruitful area for future research to think about the way that institutions and other social processes shape the moral values held by people like those who responded to our survey. For example, if we take morality to be a reflection of one's identification with particular ideological positions and beliefs (cf. Stets, 2010), then it might be these moral stances that affect the way the street population make judgments about which laws they are going to comply with and which they are not. How they come to form - or perhaps more pertinently sustain - such beliefs in the context of extreme marginalization in which they find themselves would seem a vital question to ask.

Nevertheless, understanding what policing methods work for which types of criminal behaviors amongst the street population has critical implications for regulatory theory and practice. In this context, instrumental concerns predominate over relational concerns (in some cases at least). We argue that the relationships between police and citizens central to the theory cannot be understood in a decontextualized way because structural context matters: the street population cannot comply with certain aspects of the law because if they did, they would struggle to survive. To understand the motivating power of procedural justice, we need to contextualize it and take proper account of the social groups, behaviors, norms, and laws under consideration (Lind \& Tyler, 1988; Tyler \& Lind, 1992; Tyler, 1997). A core claim of the theory is that by enhancing legitimacy and strengthening group bonds, procedural justice motivates a form of compliance with the law that is 'value neutral' - when one grants legitimacy to group authorities one does not attend to the content of particular laws because one has internalised the idea that it is morally correct in and of itself to obey the laws they enact and enforce (Tyler, 2006). Although procedural justice theory does recognize that context matters and makes predictions based on contextual factors of when procedural justice will be especially pertinent, there is little empirical work that supports those predictions. Our results suggest that this claim assumes people have a particular place in society and relationship with the police - as important group representatives - that is shared by many but not all of those with whom the latter interact. However, our respondents tended to say they refrained from offending if they judged the behavior concerned to be wrong, but they did not seem to allow police the power to make this judgment for them. We speculate that the link between the police activity and moral behavior seems to have been broken by the marginalization and exclusion of homelessness.

From one perspective this would seem to support the combination of disciplinary and more or less punitive approaches that currently characterize the policing of homelessness in the UK. Laws making it illegal to sleep rough or beg and are now coupled with zero-tolerance enforcement strategies that target street-level activities - most of them associated with homelessness (Cooper, 2016). This is combined with the activity of multi-agency teams made up of police, outreach services, local homelessness organizations, local councils and others that patrol the streets on a regular basis to make themselves visible. These teams attempt to tackle issues such as begging, rough sleeping, criminal activities and anti-social behavior (Sanders \& Albanese, 2017) by seeking to halt and reverse the alienation of the homelessness (by for example placing people into accommodation). Overall, the focus is on surveillance and exerting various forms of power to shape the behavior of the homeless in more socially desirable directions. 
That said, the association between risk perceptions and compliance with street population specific crime was weaker than that between morality and street population specific crime, and there was no significant association between risk perceptions and the other two compliance types (and noncompliance was high in our sample). One might argue that neither police strategy - relational nor instrumental - was particular effective, which would seem to focus attention even more on approaches that attempt to change the circumstances of people experiencing homelessness rather than their behaviors per se. An interesting avenue for future research is to examine whether procedural justice might prove to be effective had other outcomes related to multi-agency working be considered; or, conversely and as scholarship in the legal socialization realm (e.g., Tyler \& Trinkner, 2018) argues, whether procedural injustice drives further alienation and withdrawal from society, social institutions, and important groups such as family and peers.

\section{Strengths and Limitations}

Although our study had several strengths, like all research it was also subject to several limitations that bear on the strength of conclusions that readers can draw from our findings. First, we cannot claim causality based on our cross-sectional design and cannot rule out potential third-variable problems or issues with directionality. Second, we relied on a non-random sample, which raises the possibility of bias due to self-selection effects. Further investigation is therefore required to validate our findingsideally in the form of experimental research that goes beyond the correlational design of the present study. Longitudinal research would be useful to control for methodological effects like social desirability bias or other time-constant confounds (cf. Hamaker \& Muthén, 2020; Pina-Sánchez \& Brunton-Smith, 2020). Third, people experiencing homelessness are not a homogenous group with common motivations and challenges (Victor, 1997) and discretion in enforcement can differ between law enforcers (Bronitt \& Stenning, 2011). Different 'cohorts' might have different experiences with different police. Finally, the sample size was relatively small and our supplementary analyses did indicate a small amount of instability. It is for further research using larger samples to try to replicate these findings.

\section{Conclusion}

We need to take into account the structural context of the actors and actions that constitute crime to understand the relations between fairness, policing, and compliance. Relational concerns might not be related to compliance in the homeless context because breaking the law is critical to survival on the street or that population does not identify with or care much about being considered a member of the group the police represents (cf. Reisig et al. in press). More work is needed in this space as researchers have only just begun to apply procedural justice theory to people as socially and structurally marginal as those who participated in this study. Doing so will help to provide a better balance to the literature and enhance our understanding of these complex relationships. 


\section{References}

Allingham, M., \& Sandmo, A. (1972). Income tax evasion: A theoretical analysis. Journal of Public Economics, 1(3), 323-338.

Andreoni, J., Erard, B., \& Feinstein, J. (1998). Tax compliance. Journal of Economic Literature, 36(2), 818-860.

Anwar, S., \& Loughran, T. (2011). Testing a Bayesian learning theory of deterrence among serious juvenile offenders. Criminology, 49(3), 667-698.

Batty, E. and Reeve, K. (2011) The Hidden truth about Homelessness: experiences of single homelessness in England. London: Crisis.

Becker, G. (1968). Crime and punishment: An econometric approach. Journal of Political Economy, $76(2), 169-217$.

Bell, M. (2019). The community in criminal justice: subordination, consumption, resistance and transformation. Social science research on race, 16(1), 197-220.

Bouffard, J. A., Exum, M. L., \& Niebuhr, N. (2018). Examining the stability and predictors of deterrability across multiple offence types within a sample of convicted felons. Journal of Criminal Justice, 57(C), 76-88.

Bradford, B., Hohl, K., Jackson, J., \& MacQueen, S. (2015). Obeying the rules of the road: Procedural justice, social identity and normative compliance. Journal of Contemporary Criminal Justice, 31(2), 171-191.

Bronitt, S., \& Stenning, P. (2011). Understanding discretion in modern policing. Criminal law journal, 35, 319-332.

Brown KL, Reisig MD (2019) Procedural injustice, police legitimacy, and officer gender: A vignette based test of the invariance thesis. Behavioral Sciences and the Law, 37(6):696-710.

Cooper, V. (2016), No Fixed Abode: The continuum of policing and incarcerating the homeless, Policing, 11(/1),: 29-38.

Crisis (2018). Scrap the Act: The case for repealing the Vagrancy Act (1824). London: Crisis.

Feldman, L.C. (2004). Citizens without shelter. Ithaca and London: Cornell University Press.

Fitzpatrick, S., Johnsen, S., \& White, M. (2011), 'Multiple exclusion homelessness in the UK: Key patterns and intersections', Social Policy \& Society, 10(/4),4: 501-512.

Gau, J., \& Brunson, R. (2010). Procedural justice and order maintenance policing: A study of innercity young men's perceptions of police legitimacy. Justice Quarterly, 27(2), 255-279.

Geller, A., Fagan, J., Tyler, T., \& Link, B. G. (2014). Aggressive policing and the mental health of young urban men. American journal of public health, 104(12), 2321-2327.

Gibbs, J. (1968). Crime, punishment and deterrence. Southwestern Social Science Quarterly, 48, 515530.

Hamaker, E. L., \& Muthén, B. (2020). The fixed versus random effects debate and how it relates to centering in multilevel modeling. Psychological Methods, 25(3), 365-379.

Heuer, L., \& Stroessner, S. J. (2011). The multi-value basis of procedural justice. Journal of Experimental Social Psychology, 47(3), 541-553.

Jackson, D. B., Fahmy, C., Vaughn, M. G., \& Testa, A. (2019). Police stops among at-risk youth: Repercussions for mental health. Journal of Adolescent Health, 65(5), 627-632.

Jackson, J. (2018). Norms, normativity and the legitimacy of legal authorities: International perspectives. Annual Review of Law and Social Science, 14, 145-165.

Jackson, J., Bradford, B., Stanko, B., \& Hohl, K. (2013). Just authority? Trust in police in England and wales. Routledge: London and New York.

Jackson, J., Pósch, K., Oliveira, T. R., Bradford, B., Mendes, S. M., Natal, A. L., \& Zanetic, A. (2021, January 28). Fear and legitimacy in São Paulo, Brazil: Police-citizen relations in a high violence, high fear city. Available at PsyArXiv: https://doi.org/10.31235/osf.io/3awrz.

Jackson, J., \& Bradford, B. (2019). Blurring the distinction between empirical and normative legitimacy? A methodological commentary on "police legitimacy and citizen cooperation in China". Asian Journal of Criminology, 14, 265-289.

Johnsen, S., Fitzpatrick S., \& Watts, B. (2018). Homelessness and social control: A typology. Housing Studies, 33(7), 1106-1126.

Kyprianides, A., Stott, C., Bradford, B. (2020). 'Playing the game': Power, authority and procedural justice in interactions between police and homeless people in London. British Journal of 
Criminology.

Kyprianides A., Bradford, B., Jackson, J., Yesberg, J., Stott, C., \& Radburn, M. (2021). On the identity dynamics of police legitimacy and public cooperation among a general population and a London street population. Accepted for publication at Psychology, Public Policy \& Law.

Lee, Y.H., Cho, S. (2020). The Significance of Instrumental Pathways to Legitimacy and Public Support for Policing in South Korea: Is the Role of Procedural Fairness Too Small? Crime Law Soc Change 73, 575-603.

Lind, E. A., \& Tyler, T. R. (1988). The Social Psychology of Procedural Justice. New York: Plenum.

Lind, E.A., van den Bos, K. (2002). When fairness works: Toward a general theory of uncertainty management, Research in Organizational Behavior, 24, 181-223.

MacCoun, R.J. (2005). Voice, control and belonging: the double-edged sword of procedural fairness. Annual Review of Law and Social Science, 1, 171-201.

Mazerolle, L., Antrobus, E., Bennett, S., \& Tyler, T. (2013). Shaping citizen perceptions of police legitimacy: A randomized field trial of procedural justice. Criminology, 51(1), 33-63.

McAdams, R.H. (2017) The expressive powers of law. London: Harvard University Press

McCarthy (2013). Homelessness and identity: A critical review of the literature and theory. People, place and policy online, 7(1), 46-58.

Ministry of Justice (2010). Accommodation, homelessness and reoffending of prisoners: Results from the Surveying Prisoner Crime Reduction (SPCR) survey. Ministry of Justice.

Ministry of Justice (2019). Rough sleeping statistics Autumn 2018, England. Ministry of Housing, Communities \& Local Government.

Murphy, K., Bradford, B. \& Jackson, J. (2016). Motivating compliance behavior among offenders: procedural justice or deterrence? Criminal Justice and Behavior, 43(1), 102-118.

Muthén, B. (2011). Applications of causally defined direct and indirect effects in mediation analysis using SEM in Mplus. https://www.statmodel.com/download/causalmediation.pdf

Nagin, D. (2013). Deterrence in the twenty-first century. Crime and Justice, 42(1), 199-263.

Nagin, D.S. \& Telep, C.W. (2020). Procedural justice and legal compliance: A revisionist perspective. Criminology \& Public Policy. DOI: 10.1111/1745-9133.12499

Nagin, D.S. and Telep, C.W. (2017). Procedural justice and legal compliance. Annual Review of Law and Social Science 13: 5-28.

Papachristos, A., Meares, T., \& Fagan, J. (2012). Why do criminals obey the law? The influence of legitimacy and social networks on active gun offenders. The Journal of Criminal Law and Criminology, 102(2), 397-440.

Paternoster, R., \& Piquero, A. (1995). Reconceptualizing deterrence: An empirical test of personal and vicarious experiences. Journal of Research in Crime \& Delinquency, 32(3), 251-286.

Paternoster, R., Brame, R., Bachman, R., \& Sherman, L. (1997). Do fair procedures matter? The effect of procedural justice on spouse assault. Law \& Society Review, 31(1), 163-204.

Pina-Sánchez J, Brunton-Smith I (2020). Reassessing the relationship between procedural justice and police legitimacy. Law and Human Behavior, 44(5), 377-393.

Piquero, A., Fagan, J., Mulvey, E., Steinberg, L., \& Odgers, C. (2005). Developmental trajectories of legal socialization among serious adolescent offenders. The Journal of Criminal Law and Criminology, 96(1), 267-298.

Pratt, T. C., Cullen, F. T., Blevins, K. R., Daigle, L. E., \& Madensen, T. D. (2006). The empirical status of deterrence theory: A Meta-Analysis. In F. T. Cullen, J. P. Wright, \& K. R. Blevins (Eds.), Advances in criminological theory: Vol. 15. Taking stock: The status of criminological theory (p. 367-395). Transaction Publishers.

Pyper, D., Sturge, G., \& Cromarty, H. (2019). Rough sleepers and anti-social behavior. House of Commons Library Research Briefing: https://commonslibrary.parliament.uk/researchbriefings/cbp-7836/

Quirouette M. (2018). Community practitioners in criminal courts: Risk logics and multiplydisadvantaged individuals. Theoretical Criminology, 22(4), 582-602.

Reisig, M. D., Flippin, M., Mesko, G., \& Trinkner, R. (in press). The effects of legitimacy across urban neighborhoods: A test of the invariance thesis. Crime \& Delinquency.

Reisig, M., Tankebe, J., \& Mesko, G. (2014). Compliance with the law in Slovenia: The role of procedural justice and police legitimacy. European Journal on Criminal Policy and Research, 
20(2), 259-276.

Robinson, T. (2019), No right to rest: Police enforcement patterns and quality of life consequences of the criminalization of homelessness, Urban Affairs Review, 55(/1),: 41-73.

Sanders, B. \& Albanese, F. (2017). An examination of the scale and impact of enforcement interventions on street homeless people in England and Wales. London: Crisis.

Skitka, L.J., Houston, D.A. (2001). When due process is of no consequence: Moral mandates and presumed defendant guilt or innocence. Social Justice Research, 14(3), 305-326.

Stets J.E. (2010). The social psychology of the moral identity. In: Hitlin S., Vaisey S. (eds) Handbook of the Sociology of Morality. Handbooks of Sociology and Social Research. Springer, New York, NY.

Stuart, F. (2015), 'On the streets, under arrest: Policing homelessness in the 21st Century', Sociology Compass, 9(/11),: 940-950.

Sunshine, J., \& Tyler, T. (2003). The role of procedural justice and legitimacy in shaping public support for policing. Law \& Society Review, 37(3), 513-548.

Tankebe, J. (2009). Public cooperation with the police in Ghana: Does procedural fairness matter? Criminology 47(4): 1265-1293.

Tittle, C. (1969). Crime rates and legal sanctions. Social Problems, 16, 409-423.

Trinkner, R. (2019). Clarifying the contours of the police legitimacy measurement debate: A response to Cao and Graham. Asian Journal of Criminology, 14(4), 309-335.

Trinkner, R., Jackson, J., \& Tyler, T. R. (2018). Bounded authority: Expanding "appropriate" police behavior beyond procedural justice. Law and Human Behavior, 42(3), 280-293.

Tyler, T. (1990). Why people obey the law. New Haven, CT: Yale University Press.

Tyler, T. (2006). Psychological perspectives on legitimacy and legitimation. Annual Review of Psychology, 57(1), 375-400.

Tyler, T. R. (1997). The psychology of legitimacy: A relational perspective on voluntary deference to authorities. Personality and Social Psychology Review, 1(4), 323-345.

Tyler, T. R., \& Blader, S. L. (2003). The group engagement model: Procedural justice, social identity, and cooperative behavior. Personality and Social Psychology Review, 7(4), 349 -361.

Tyler, T. R., \& Lind, E. A. (1992). A relational model of authority in groups. Advances in Experimental Social Psychology, 25, 115-191.

Tyler, T. R., \& Trinkner, R. (2018). Why children follow rules: Legal socialization and the development of legitimacy. New York: Oxford University Press.

Victor, C.R. (1997). The health of homeless people in Britain. European Journal of Public Health, 7(4), $398-404$.

Vitale, A. (2018). The End of Policing. Brooklyn: Verso.

Walters, G. D. \& Bolger, P. C. (2019). Procedural justice perceptions, legitimacy beliefs, and compliance with the law: A meta-analysis. Journal of Experimental Criminology, 15(3), 341-372.

Walters, G. D., \& Morgan, R. D. (2018). Assessing criminal thought content: preliminary validation of the criminal thought content inventory (CTCI). Psychology, Crime, and Law, 1(1): 603-620.

White, M. D., Mulvey, P., \& Dario, L. M. (2016). Arrestees' perceptions of the police: exploring procedural justice, legitimacy, and willingness to cooperate with police across offender types. Criminal Justice and Behavior, 43(3), 343-364.

Williams, K., \& Hawkins, R. (1986). Perceptual research on general deterrence: A critical review. Law \& Society Review, 20(4), 545-572.

Wolfe, S. E., Nix, J., Kaminski, R. \& Rojek, J. (2016). Is the effect of procedural justice on police legitimacy invariant? Testing the generality of procedural justice and competing antecedents of legitimacy. Journal of Quantitative Criminology, 32(2), 253-282. 


\section{Tables and figures}

Table 1. Percentage of participants who indicated that they often or sometimes or rarely or never engage in lowlevel, street population-specific, and high-level criminal activities.

\begin{tabular}{|c|c|c|c|c|c|c|}
\hline \multicolumn{7}{|c|}{ Engagement in low-level criminal activities (\%) } \\
\hline & Often & Sometimes & Rarely & Never & $M$ & $S D$ \\
\hline Buy stolen good & 19.0 & 24.0 & 16.5 & 40.5 & 2.79 & 1.17 \\
\hline Illegal waste disposal & 18.5 & 18.5 & 23.0 & 40.0 & 2.85 & 1.14 \\
\hline Shop lifting & 18.0 & 20.0 & 19.0 & 57.0 & 1.87 & 1.16 \\
\hline Vandalism & 15.0 & 12.0 & 14.5 & 58.5 & 3.17 & 1.13 \\
\hline Cannabis & 33.5 & 21.0 & 13.5 & 32.0 & 2.44 & 1.25 \\
\hline \multicolumn{7}{|c|}{ Engagement in street population-specific criminal activities (\%) } \\
\hline & Often & Sometimes & Rarely & Never & $M$ & $S D$ \\
\hline Alcohol on street* & 37.5 & 19.0 & 15.5 & 28.0 & 2.34 & 1.24 \\
\hline Begging & 38.0 & 11.5 & 13.0 & 37.5 & 2.50 & 1.33 \\
\hline Rough sleeping & 39.0 & 17.5 & 14.5 & 29.0 & 2.34 & 1.26 \\
\hline Spice**/heroin & 32.0 & 15.0 & 11.5 & 41.5 & 2.63 & 1.31 \\
\hline Anti-social behavior & 26.5 & 13.0 & 18.5 & 42.0 & 2.76 & 1.25 \\
\hline \multicolumn{7}{|c|}{ Engagement in high-level criminal activities (\%) } \\
\hline & Often & Sometimes & Rarely & Never & $M$ & $S D$ \\
\hline Burglary & 14.5 & 15.0 & 10.5 & 60.0 & 3.16 & 1.15 \\
\hline Robbery & 9.5 & 14.5 & 10.0 & 66.0 & 3.33 & 1.04 \\
\hline Theft from person & 12.5 & 16.0 & 7.0 & 64.5 & 3.24 & 1.12 \\
\hline $\begin{array}{l}\text { Theft from vulnerable } \\
\text { person }\end{array}$ & 11.6 & 10.1 & 11.1 & 67.3 & 3.34 & 1.06 \\
\hline Violence & 11.0 & 14.0 & 12.5 & 62.5 & 3.27 & 1.07 \\
\hline
\end{tabular}

* Drinking alcohol on the street is generally permissible in the UK, although it is often prohibited by local statutes in many areas where the street population congregate.

** Spice is a laboratory-created cannabis substitute. We place it in the category of offences specific to the street population, whereas cannabis is in the category of mundane/low-level offences, because it is a stronger and cheaper than the latter, making it appealing to some of society's most vulnerable groups, including the homeless. Culturally, the drug is closely associated with homelessness and other forms of extreme marginality. 
Running Head: Homelessness and Compliance with the Law

Table 2. Descriptive statistics and correlations between key variables

\begin{tabular}{|c|c|c|c|c|c|c|c|c|c|c|c|c|c|c|}
\hline & $M$ & $S D$ & 1 & 2 & 3 & 4 & 5 & 6 & 7 & 8 & 9 & 10 & 11 & 12 \\
\hline 1.Procedural justice & 3.04 & 1.11 & & & & & & & & & & & & \\
\hline 2.Police legitimacy & 2.94 & 1.02 & $\begin{array}{l}.77 \\
<.001\end{array}$ & & & & & & & & & & & \\
\hline 3.Gen effectiveness & 2.84 & 1.03 & $\begin{array}{l}\mathbf{. 9 1} \\
<.001\end{array}$ & $\begin{array}{l}.73 \\
<.001\end{array}$ & & & & & & & & & & \\
\hline 4.SP effectiveness & 2.80 & 1.06 & $\begin{array}{l}\mathbf{. 8 4} \\
<.001\end{array}$ & $\begin{array}{l}\mathbf{. 6 5} \\
<.001\end{array}$ & $\begin{array}{l}.88 \\
<.001\end{array}$ & & & & & & & & & \\
\hline 5.Morality low-level & 2.92 & .95 & $\begin{array}{l}\mathbf{3 4} \\
<.001\end{array}$ & $\begin{array}{l}. \mathbf{4 2} \\
<.001\end{array}$ & $\begin{array}{l}.39 \\
<.001\end{array}$ & $\begin{array}{l}. \mathbf{4 0} \\
<.001\end{array}$ & & & & & & & & \\
\hline 6.Morality SP & 2.79 & .95 & $\begin{array}{l}.29 \\
.005\end{array}$ & $\begin{array}{l}.37 \\
<.001\end{array}$ & $\begin{array}{l}.32 \\
.001\end{array}$ & $\begin{array}{l}.33 \\
.001\end{array}$ & $\begin{array}{l}\mathbf{. 9 2} \\
<.001\end{array}$ & & & & & & & \\
\hline 7.Morality high-level & 3.40 & .90 & $\begin{array}{l}\mathbf{3 4} \\
<.001\end{array}$ & $\begin{array}{l}. \mathbf{4 0} \\
<.001\end{array}$ & $\begin{array}{l}.47 \\
<.001\end{array}$ & $\begin{array}{l}\mathbf{. 3 9} \\
<.001\end{array}$ & $\begin{array}{l}.89 \\
<.001\end{array}$ & $\begin{array}{l}.91 \\
<.001\end{array}$ & & & & & & \\
\hline 8.Risk low-level & 2.29 & .98 & $\begin{array}{l}.23 \\
.030\end{array}$ & $\begin{array}{l}.26 \\
.005\end{array}$ & $\begin{array}{l}.31 \\
.002\end{array}$ & $\begin{array}{l}.26 \\
.012\end{array}$ & $\begin{array}{l}. \mathbf{4 3} \\
<.001\end{array}$ & $\begin{array}{l}.32 \\
<.001\end{array}$ & $\begin{array}{l}.39 \\
<.001\end{array}$ & & & & & \\
\hline 9.Risk SP & 2.39 & .94 & $\begin{array}{l}.27 \\
.005\end{array}$ & $\begin{array}{l}.29 \\
.003\end{array}$ & $\begin{array}{l}.34 \\
.001\end{array}$ & $\begin{array}{l}.28 \\
.006\end{array}$ & $\begin{array}{l}. \mathbf{4 6} \\
<.001\end{array}$ & $\begin{array}{l}.33 \\
.001\end{array}$ & $\begin{array}{l}.33 \\
.001\end{array}$ & $\begin{array}{l}. \mathbf{4 0} \\
<.001\end{array}$ & & & & \\
\hline 10.Risk high-level & 2.62 & 1.10 & $\begin{array}{l}.28 \\
.003\end{array}$ & $\begin{array}{l}.25 \\
.007\end{array}$ & $\begin{array}{l}.35 \\
<.001\end{array}$ & $\begin{array}{l}.24 \\
.012\end{array}$ & $\begin{array}{l}.24 \\
.016\end{array}$ & $\begin{array}{l}.16 \\
.115\end{array}$ & $\begin{array}{l}.25 \\
.023\end{array}$ & $\begin{array}{l}\mathbf{. 8 4} \\
<.001\end{array}$ & $\begin{array}{l}. \mathbf{9 0} \\
<.001\end{array}$ & & & \\
\hline 11.Low-level compliance & 2.82 & .98 & $\begin{array}{l}. \mathbf{4 1} \\
<.001\end{array}$ & $\begin{array}{l}. \mathbf{4 3} \\
<.001\end{array}$ & $\begin{array}{l}.48 \\
<.001\end{array}$ & $\begin{array}{l}.41 \\
<.001\end{array}$ & $\begin{array}{l}.77 \\
<.001\end{array}$ & $\begin{array}{l}.67 \\
<.001\end{array}$ & $\begin{array}{l}.76 \\
<.001\end{array}$ & $\begin{array}{l}.36 \\
<.001\end{array}$ & $\begin{array}{l}.36 \\
<.001\end{array}$ & $\begin{array}{l}.26 \\
.010\end{array}$ & & \\
\hline 12. SP compliance & 2.51 & 1.14 & $\begin{array}{l}.24 \\
.018\end{array}$ & $\begin{array}{l}.29 \\
.006\end{array}$ & $\begin{array}{l}.31 \\
.002\end{array}$ & $\begin{array}{l}.31 \\
.002\end{array}$ & $\begin{array}{l}.54 \\
<.001\end{array}$ & $\begin{array}{l}\mathbf{. 5 8} \\
<.001\end{array}$ & $\begin{array}{l}\mathbf{. 6 2} \\
<.001\end{array}$ & $\begin{array}{l}.33 \\
.002\end{array}$ & $\begin{array}{l}. \mathbf{4 0} \\
<.001\end{array}$ & $\begin{array}{l}.28 \\
.005\end{array}$ & $\begin{array}{l}\mathbf{. 8 8} \\
<.001\end{array}$ & \\
\hline 13.High-level compliance & 3.27 & 1.01 & $\begin{array}{l}\mathbf{. 5 4} \\
<.001 \\
\end{array}$ & $\begin{array}{l}. \mathbf{5 2} \\
<.001 \\
\end{array}$ & $\begin{array}{l}.61 \\
<.001 \\
\end{array}$ & $\begin{array}{l}\mathbf{. 5 8} \\
<.001 \\
\end{array}$ & $\begin{array}{l}.66 \\
<.001 \\
\end{array}$ & $\begin{array}{l}.62 \\
<.001 \\
\end{array}$ & $\begin{array}{l}\mathbf{. 8 2} \\
<.001 \\
\end{array}$ & $\begin{array}{l}. \mathbf{3 6} \\
.001 \\
\end{array}$ & $\begin{array}{l}.38 \\
.001 \\
\end{array}$ & $\begin{array}{l}.28 \\
.017 \\
\end{array}$ & $\begin{array}{l}\mathbf{8 6} \\
<.001 \\
\end{array}$ & $\begin{array}{l}.76 \\
<.001 \\
\end{array}$ \\
\hline
\end{tabular}


Table 3. Standardized regression coefficients for direct and indirect paths in the SEM models

\begin{tabular}{|c|c|c|c|c|c|}
\hline \multicolumn{6}{|l|}{ Low-Level Compliance Model } \\
\hline & Direct paths & & $b$ & $S E$ & $p$ \\
\hline & \multirow{2}{*}{ Procedural justice to } & Legitimacy & .80 & .04 & $<.001$ \\
\hline & & Low-level compliance & -.28 & .47 & .55 \\
\hline & Legitimacy to & Low-level compliance & .27 & .17 & .12 \\
\hline & Risk of sanction to & Low-level compliance & .20 & .11 & .08 \\
\hline & \multirow{2}{*}{ Police effectiveness to } & Risk of sanction & .39 & .09 & $<.001$ \\
\hline & & Low-level compliance & .09 & .41 & .82 \\
\hline & Morality to & Low-level compliance & .71 & .09 & $<.001$ \\
\hline & \multicolumn{5}{|l|}{ Indirect paths } \\
\hline & PJ to Low-level compliance via & Legitimacy & .22 & .14 & .12 \\
\hline & Effectiveness to Low-level compliance via & Risk of sanction & .08 & .04 & .08 \\
\hline \multicolumn{6}{|c|}{ Street Population Compliance Model } \\
\hline & Direct paths & & $B$ & $S E$ & $p$ \\
\hline & \multirow{2}{*}{ Procedural justice to } & Legitimacy & .79 & .04 & $<.001$ \\
\hline & & Street pop compliance & -.35 & .37 & .34 \\
\hline & Legitimacy to & Street pop compliance & .26 & .22 & .23 \\
\hline & Risk of sanction to & Street pop compliance & .32 & .11 & .002 \\
\hline & \multirow[t]{2}{*}{ Police effectiveness to } & Risk of sanction & .39 & .09 & $<.001$ \\
\hline & & Street pop compliance & .06 & .28 & .83 \\
\hline & Morality to & Street pop compliance & .57 & .10 & $<.001$ \\
\hline & Indirect paths & & & & \\
\hline & PJ to Street pop compliance via & Legitimacy & .20 & .17 & .24 \\
\hline & Effectiveness to Street pop compliance via & Risk of sanction & .13 & .05 & .01 \\
\hline
\end{tabular}

\section{High-Level Compliance Model}

\section{Direct paths}

Procedural justice to

Legitimacy to

Risk of sanction to

Police effectiveness to

\section{Legitimacy}

High-level compliance

High-level compliance

High-level compliance

Risk of sanction

High-level compliance

$\begin{array}{lll}B & S E & p \\ \mathbf{. 7 9} & \mathbf{. 0 4} & <.001 \\ -.24 & .34 & .23 \\ .25 & .14 & .09 \\ .07 & .10 & .50 \\ .35 & \mathbf{. 0 9} & <.001 \\ .29 & .24 & .23\end{array}$


Running Head: Homelessness and Compliance with the Law

Morality to

Indirect path

PJ to High-level compliance via

Effectiveness to High-level compliance via Note. bolded b, SE, and $p$ values were statistically significant
High-level compliance

$<.001$

Legitimacy

.20

Risk of sanction 
Figure 1. Specified direct and indirect paths of the models

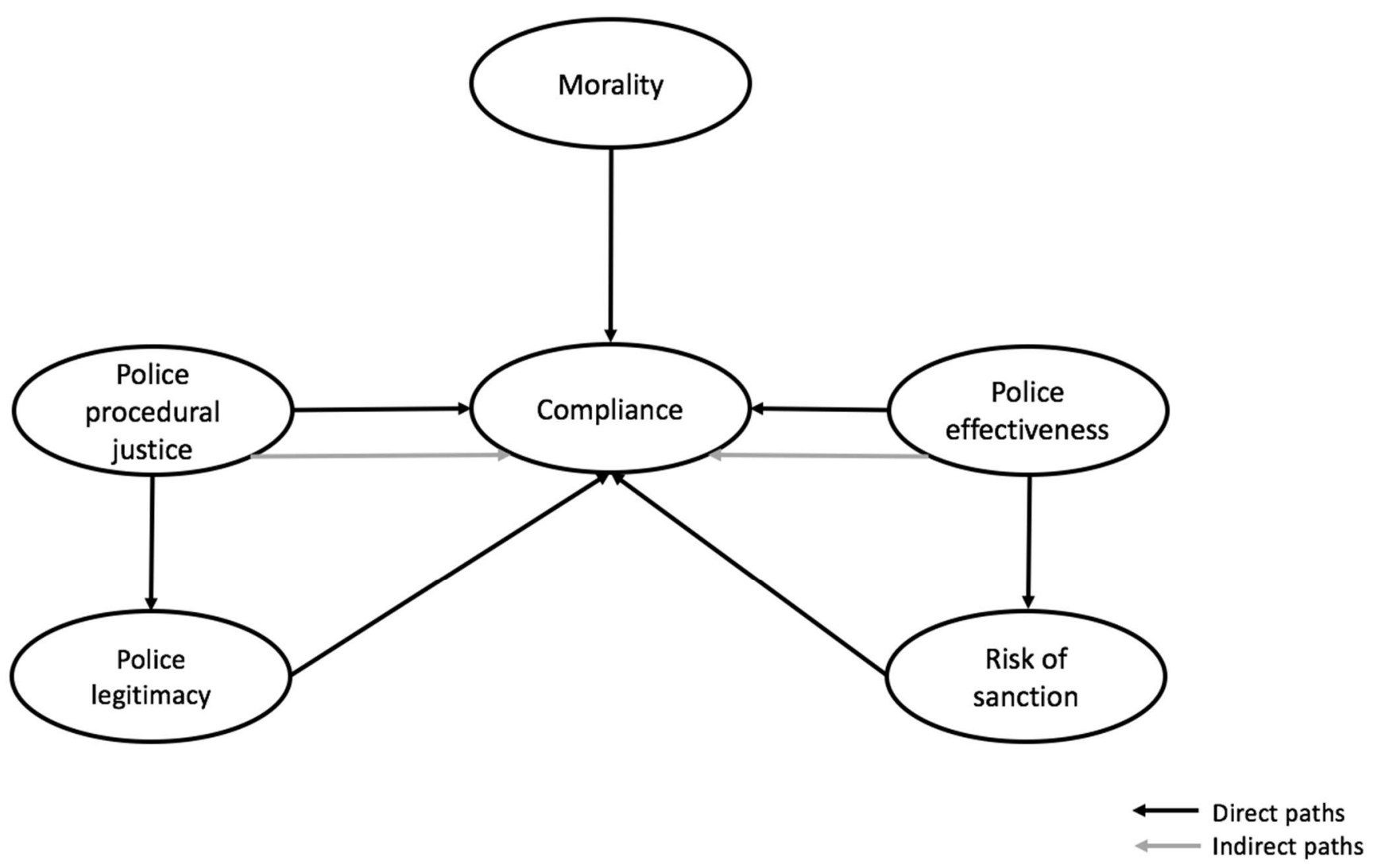




\section{Appendix: Measures}

\section{Perceived Police Procedural Justice $(\mathrm{a}=\mathbf{8 9})$}

$1=$ Strongly Disagree, 2 = Disagree, $3=$ Neither Agree nor Disagree, $4=$ Agree, $5=$ Strongly Agree)

The police make decisions based on facts $\{\mathrm{PJ} 1\}$

The police explain their decisions to the people they deal with $\{\mathrm{PJ} 2\}$

The police treat people with respect $\{\mathrm{PJ} 3\}$

\section{Perceived Police Legitimacy $(\mathrm{a}=\mathbf{. 9 3})$}

$1=$ Strongly Disagree, $2=$ Disagree, $3=$ Neither Agree nor Disagree, $4=$ Agree, $5=$ Strongly Agree)

I feel a moral obligation to obey the police $\{$ OBEY1\}

I feel a moral duty to support the decisions of police officers, even if I disagree with them \{OBEY2\}

I feel a moral duty to obey the instructions of police officers, even when I don't understand the reasons behind them $\{$ OBEY 3$\}$

I support the way the police usually act $\{$ NORM1\}

The police usually act in ways that are consistent with my own ideas about what is right and wrong \{NORM2\}

The police stand up for values that are important for people like me \{NORM3\}

\section{Perceived Police Effectiveness $(\mathrm{a}=\mathbf{. 9 2})$}

$1=$ Strongly Disagree, 2 = Disagree, $3=$ Neither Agree nor Disagree, $4=$ Agree, $5=$ Strongly Agree)

The police are effective at tackling drug dealing and drug use $\{\mathrm{EFF} 1\}$

The police are effective at responding to emergencies promptly $\{$ EFF 2$\}$

The police are effective at providing a visible patrolling presence $\{\mathrm{EFF} 3\}$

The police are good at moving people on and stopping them from begging $\{$ SPEFF1\}

The police are good at stopping people from drinking alcohol where they shouldn't be \{SPEFF1\}

The police are good at stopping people from taking drugs $\{$ SPEFF1\}

\section{Compliance}

$1=$ Often, 2 = Sometimes, 3 = Rarely, $4=$ Never

How often during the past year have you...?

Low-level compliance $(\mathbf{a}=\mathbf{. 9 0})$

Bought something that you thought might have been stolen $\{$ Comp1a\}

Illegally disposed of trash or litter ('fly tipping') \{Complb

Taken something from a shop without paying for it $\{$ Complc $\}$

Vandalised public property $\{$ Compld $\}$

Bought or used drugs such as cannabis $\{$ Comple\}

Compliance with behaviors specific to the street population $(\mathbf{a}=\mathbf{. 9 4})$

Drank alcohol on the street $\{$ Comp2a $\}$

Begged on the street or elsewhere $\{$ Comp2b $\}$

Rough slept in areas that you know it is not permitted $\{$ Comp2c $\}$

Bought or used drugs such as spice or heroin $\{$ Comp2d

Engaged in anti-social behavior such as being violent, rowdy or inconsiderate to others $\{$ Comp2e\}

High-level compliance $(\mathbf{a}=\mathbf{. 9 5})$

Stolen something, or attempted to steal something, from a house or unauthorised premise (burglary) \{Comp3a\}

Stolen something with the use of force/ weapon or threat to use force/ weapon (robbery) \{Comp3b\}

Stolen something from a person (e.g. pickpocket) \{Comp3c\}

Stolen something from a vulnerable person (e.g. an old lady) \{Comp3d\}

Been physically violent against someone else not in self-defence (e.g. started a fight with someone) \{Comp3e\}

\section{Morality}

$1=$ not wrong at all, $2=$ not too wrong, $3=$ somewhat wrong, $4=$ very wrong

How wrong do you think the following behaviors are...?

Compliance with low-level crimes $(\mathbf{a}=\mathbf{. 9 2})$

Buying something that you think might have been stolen \{Morla\}

Illegally disposing of trash or litter ('fly tipping') \{Morlb

Taking something from a shop without paying for it $\{$ Morlc\} 
Vandalising public property $\{$ Morld

Buying or using drugs such as cannabis $\{$ Morle\}

Compliance with behaviors specific to the street population $(\mathbf{a}=\mathbf{. 9 0})$

Drinking on the street $\{$ Mor2a

Begging on the street or elsewhere $\{$ Mor $2 \mathrm{~b}$ \}

Rough sleeping in areas that you know it is not permitted $\{$ Mor2c $\}$

Buying or using drugs such as spice or heroin $\{$ Mor2d

Engaging in anti-social behavior such as being violent, rowdy or inconsiderate to others \{Mor2e\}

Compliance with high-level crimes $(\mathbf{a}=\mathbf{. 9 7})$

Stealing something, or attempting to steal something, from a house or unauthorised premise \{Mor3a\}

Stealing something with the use of force/ weapon or threat to use force/ weapon (robbery) \{Mor3b\}

Stealing something from a person (e.g. pickpocket) $\{$ Mor3c\}

Stealing something from a vulnerable person (e.g. old lady) \{Mor3d\}

Being physically violent against someone else not in self-defence (e.g. started a fight with someone) \{Mor3e\}

\section{Perceived Risk of Sanction}

$1=$ not at all likely, 2 = not very likely, 3 = fairly likely, 4 = very likely

How likely do you think it is that you would be caught and punished (by being fined and/ or arrested) if you did any of the following behaviors...?

Compliance with low-level crimes $(\mathbf{a}=\mathbf{. 9 3})$

Bought something that you thought might have been stolen \{Risk1a\}

Illegally disposed of trash or litter ('fly tipping') \{Risk $1 \mathrm{~b}\}$

Taken something from a shop without paying for it $\{$ Risk1c\}

Vandalised public property $\{$ Risk1d\}

Bought or used drugs such as cannabis $\{$ Risk1e\}

Compliance with behaviors specific to the street population $(\mathbf{a}=\mathbf{. 9 2})$

Drank alcohol on the street $\{$ Risk2a $\}$

Begged on the street or elsewhere $\{$ Risk $2 b$ \}

Rough slept in areas that you know it is not permitted \{Risk2c\}

Bought or used drugs such as spice or heroin $\{$ Risk2d

Engaged in anti-social behavior such as being violent, rowdy or inconsiderate to others \{Risk2e\}

Compliance with high-level crimes $(\mathbf{a}=\mathbf{. 9 7})$

Stole something, or attempted to steal something, from a house or unauthorised premise (burglary) \{Risk3a\}

Stole something with the use of force/ weapon or threat to use force/ weapon (robbery) \{Risk3b

Stole something from a person (e.g. pickpocket) \{Risk3c\}

Stole something from a vulnerable person (e.g. an old lady) \{Risk3d\}

Were physically violent against someone else not in self-defence (e.g. started a fight with someone) \{Risk3e\} 


\section{Online Supplementary Materials}

Table of Contents

(1) SEM Model Results without Specifying Indirect Effects (pp. 2-3)

(2) SEM Model whereby we regressed All Latent Variables in the Model on Gender, Age, Ethnicity, and Country of Birth (p. 3-5)

(3) Ordinal Regression Models on each of the Individual Compliance Items (p. 6)

(4) Confirmatory Factor Analysis: Differentiating versus Combining Normative Alignment and Duty to Obey as Legitimacy (p. 7)

(5) Bayesian and Sensitivity Analyses (pp. 8-11) 
1. SEM Model Results of Direct Paths (the results remained the same)

\begin{tabular}{|c|c|c|c|}
\hline \multicolumn{4}{|l|}{ Low-Level Compliance Model } \\
\hline & \multicolumn{2}{|l|}{ Direct paths } & $b$ \\
\hline & \multirow[t]{2}{*}{ Procedural justice to } & Legitimacy & .80 \\
\hline & & Low-level compliance & -.28 \\
\hline & Legitimacy to & Low-level compliance & .27 \\
\hline & Risk of sanction to & Low-level compliance & .20 \\
\hline & \multirow[t]{2}{*}{ Police effectiveness to } & Risk of sanction & .39 \\
\hline & & Low-level compliance & .09 \\
\hline & Morality to & Low-level compliance & .71 \\
\hline \multicolumn{4}{|c|}{ Street Population Compliance Model } \\
\hline & \multicolumn{2}{|l|}{ Direct paths } & $B$ \\
\hline & \multirow[t]{2}{*}{ Procedural justice to } & Legitimacy & .79 \\
\hline & & Street pop compliance & -.35 \\
\hline & Legitimacy to & Street pop compliance & .26 \\
\hline & Risk of sanction to & Street pop compliance & .32 \\
\hline & \multirow{2}{*}{ Police effectiveness to } & Risk of sanction & .39 \\
\hline & & Street pop compliance & .06 \\
\hline & Morality to & Street pop compliance & .57 \\
\hline \multicolumn{4}{|l|}{ High-Level Compliance Model } \\
\hline & \multicolumn{2}{|l|}{ Direct paths } & $B$ \\
\hline & \multirow{2}{*}{ Procedural justice to } & Legitimacy & .79 \\
\hline & & High-level compliance & -.24 \\
\hline & Legitimacy to & High-level compliance & .25 \\
\hline & Risk of sanction to & High-level compliance & .07 \\
\hline & \multirow{2}{*}{ Police effectiveness to } & Risk of sanction & .35 \\
\hline & & High-level compliance & .29 \\
\hline & Morality to & High-level compliance & .68 \\
\hline
\end{tabular}

Note: We did not estimate indirect effects due to potentially insufficient statistical power. 
2. SEM Model whereby we regressed All Latent Variables in the Model on Gender, Age, Ethnicity, and Country of Birth (the pattern of results remained the same)

\section{Low-Level Compliance Model}

\begin{tabular}{|c|c|c|c|}
\hline & \multicolumn{3}{|l|}{ Direct paths } \\
\hline & \multirow[t]{2}{*}{ Procedural justice to } & Legitimacy & .78 \\
\hline & & Low-level compliance & -.19 \\
\hline & Legitimacy to & Low-level compliance & .16 \\
\hline & Risk of sanction to & Low-level compliance & .17 \\
\hline & \multirow[t]{2}{*}{ Police effectiveness to } & Risk of sanction & .35 \\
\hline & & Low-level compliance & .21 \\
\hline & Morality to & Low-level compliance & .66 \\
\hline \multicolumn{4}{|c|}{ Street Population Compliance Model } \\
\hline & \multicolumn{2}{|l|}{ Direct paths } & $B$ \\
\hline & \multirow[t]{2}{*}{ Procedural justice to } & Legitimacy & .77 \\
\hline & & Street pop compliance & -.21 \\
\hline & Legitimacy to & Street pop compliance & .14 \\
\hline & Risk of sanction to & Street pop compliance & .27 \\
\hline & Police effectiveness to & Risk of sanction & .32 \\
\hline & & Street pop compliance & .16 \\
\hline & Morality to & Street pop compliance & .48 \\
\hline \multicolumn{4}{|l|}{ High-Level Compliance Model } \\
\hline & Direct paths & & $B$ \\
\hline & \multirow{2}{*}{ Procedural justice to } & Legitimacy & .78 \\
\hline & & High-level compliance & -.15 \\
\hline & Legitimacy to & High-level compliance & .17 \\
\hline & Risk of sanction to & High-level compliance & .03 \\
\hline & \multirow[t]{2}{*}{ Police effectiveness to } & Risk of sanction & .37 \\
\hline & & High-level compliance & .28 \\
\hline & Morality to & High-level compliance & .66 \\
\hline
\end{tabular}


3. Regression Models on Each of the Individual Compliance Items (the pattern of results remained the same).

\begin{tabular}{lllllllll}
\hline Predictors & \multicolumn{2}{l}{ Low-level compliance items } & \multicolumn{2}{l}{ SP compliance items } & \multicolumn{3}{l}{ High-level cc } \\
& $b$ & $S E$ & $p$ & $b$ & $S E$ & $p$ & $b$ & $S$ \\
Procedural justice & $-.01-.10$ & $.10-.15$ & $.14-.95$ & $-.08--.29$ & $.12-.13$ & $.05-.42$ & $.01-.09$ & .0 \\
Legitimacy & $.03-.17$ & $.10-.11$ & $.29-.78$ & $.08-.19$ & $.12-.13$ & $.06-.47$ & $.07-.21$ & .0 \\
Risk of sanction & $.01-.08$ & $.04-.08$ & $.53-.94$ & $\mathbf{. 0 6}-.22$ & $\mathbf{. 0 9}-. \mathbf{1 0}$ & $<.05$ & $.02-.09$ & .0 \\
Police effectiveness & $.01-.10$ & $-.01-.11$ & $.31-.97$ & $-.01-.09$ & $.12-.14$ & $.41-.99$ & $.06-.20$ & .0 \\
Morality & $\mathbf{. 4 7 - . 5 4}$ & $\mathbf{. 0 1}-\mathbf{. 0 9}$ & $<.001$ & $\mathbf{. 3 4 - . 4 7}$ & $\mathbf{. 1 0}-. \mathbf{1 1}$ & $<.001$ & $\mathbf{. 4 9 - . 5 1}$ & $\mathbf{. 0}$ \\
\hline
\end{tabular}

Note: Range of $b, S E, p$ provided in the table for ease of presentation. 
4. Confirmatory Factor Analysis: Differentiating Normative Alignment and Duty to Obey (as two separate constructs of legitimacy) versus Combining Normative Alignment and Duty to Obey into One 'Legitimacy' Latent Construct

We tested two separate measurement models, one that differentiated normative alignment and duty to obey (as two separate constructs of legitimacy), and one that combined normative alignment and duty to obey into one 'legitimacy' latent construct; and both models fit the data well (where one typically looks for CFI >.95; TLI >.95; RMSEA <.08 - see Hu \& Bentler, 1999).

CFA results for model that differentiated normative alignment and duty to obey (as two separate constructs of legitimacy)

The model that included ten covarying latent constructs of police procedural justice, normative alignment, duty to obey, police general effectiveness, police street population specific effectiveness, perceived risk of sanction, morality, compliance with low-level crimes, compliance with behaviours specific to the street population, and compliance with high-level crimes produced adequate fit indices $($ Chi-Square $=1876.93, \mathrm{df}=1561, p=<.001 ; \mathrm{RMSEA}=.05[.04, .05] ; \mathrm{CFI}=.98 ; \mathrm{TLI}=.98)$, with all standardized factor loadings $>.8$.

CFA results for model that combined normative alignment and duty to obey into one 'legitimacy' latent construct

The model that included nine covarying latent constructs of police procedural justice, police legitimacy, police general effectiveness, police street population specific effectiveness, perceived risk of sanction, morality, compliance with low-level crimes, compliance with behaviours specific to the street population, and compliance with high-level crimes produced adequate fit indices (Chi-Square = $1884.833, \mathrm{df}=1574, p=<.001 ; \mathrm{RMSEA}=.04[.04, .05] ; \mathrm{CFI}=.99 ; \mathrm{TLI}=.98)$, with all standardized factor loadings $>.8$.

Although differences were negligible comparing the approximate fit statistics between measurement models that combined normative alignment and duty to obey into one 'legitimacy' latent construct, and models that differentiated normative alignment and duty to obey as two separate constructs, we opted for the one latent construct of legitimacy for a simpler analytical model. 


\section{Bayesian and Sensitivity Analyses (the pattern of results remained the same)}

\section{Method}

\section{Analytical approach}

The current study had a relatively small sample size $(\mathrm{N}=200)$. In case of small sample sizes, the traditional frequentist approach of structural equation modelling, which relies on maximum likelihood estimation, tends to produce biased point estimates and unreliable standard errors due to the lack of statistical power (McNeish \& Stapelton, 2014). We used Bayesian Structural Equation Modelling (BSEM) to mitigate such limitations,. Recent literature reviews have established that BSEM outperforms frequentist SEMs in case of carefully considered priors by providing less biased estimates, increased efficiency, and an increased discovery rate of nonnull effects (Muthén \& Asparouhov, 2012; Smid et al. 2019). Notably, diffuse or non-informative priors tend to perform as badly or even worse than models estimated in a frequentist framework (Smid et al., 2019). Simulation studies have shown that weak priors can work well in BSEM providing meaningful improvement compared to frequentist models and BSEM with non-informative priors (McNeish, 2016).

Bayesian estimation is different from the commonly pursued frequentist SEM in several meaningful ways.

First, by default, BSEM does not posit a distribution to either of the estimated parameters. However, and importantly, prior distribution can be included in the modelling, aiding the accuracy of the estimation which is especially germane in case of small sample sizes.

Second, BSEM considers the data as fixed (i.e., does not carry out resampling), and the parameters and posterior distributions are estimated accordingly. It follows, that Bayesian approaches do not rely on asymptotic normality, instead a sampling-based method (most commonly Markov chain Monte Carlo $-\mathrm{MCMC}$ ) is used for statistical inference.

Third, the interpretation of the estimates is also different for BSEMs. Instead of confidence intervals, MCMC intervals (i.e., 'credibility' or 'posterior probability' intervals - we will refer to them as CIs) are taken from percentiles of the posterior distributions for each parameter. This posterior distribution is calculated by relying on the prior distribution (which is set by the researcher) and the likelihood (which is derived from the given dataset). The smaller the sample, the bigger weight the prior distribution receives, which means that the more exposed the analysis can get to the researchers informed intuition (van de Schoot et a al. 2014).

We ran our model using informative priors (which are sometimes referred to as subjective or thoughtful priors). For the variance components, we used a half-Cauchy prior which is the normalized precision parameter of the scaled gamma distribution and works especially well with small samples (cf. Gelman, 2006; Polson \& Scott, 2012 and McNeish \& Stapleton, 2016). We adjusted the parameters for parameter range based on the possible values of each construct (i.e., according to the scale they were measured on), while we also considered the expectation whether an estimate will be negative/positive, with the expected direction of the relationship weighted (e.g., in case of a positive relationship: $[-1, \infty]$ ). We specified these informative priors using best-practice recommendations (cf. Smid et al. 2019; Zondervan-Zwijnenburg et al. 2017) and helped the modelling by limiting the admissible parameter space (i.e., ignoring non-sensical and unlikely values) thus, improving the precision by making the posterior distribution narrower. Crucially, these informative priors can be considered fairly weak and thus, are unlikely to overpower the parameter estimation.

Finally, to gauge the dependence of our results on the specified priors, we carried out sensitivity analysis following the steps recommended by van Erp, Mulder, and Oberski (2018). We left the priors for the variances unchanged and only modified the priors for the parameter estimates as they were of primary importance to our results. In particular, we ran three models: (1) one with non-informative priors (i.e., $-\infty, \infty]),(2)$ one with data-driven priors, where the priors were generated post-hoc based on the emerging 
results (this is bad practice and should not be done, but could demonstrate how the results would change had we used the strongest possible priors), and (3) finally, the model as specified above. For each sensitivity analysis, certain boundaries need to specified which, if breached, the results are deemed sensitive. In our case, we were interested in assessing to what extent the strength of the parameter estimates and their corresponding CIs would change, and whether they would include zero.

Table 1 summarizes the results from the sensitivity analysis, indicating the consistencies across the various models, had we used other priors. In case of CIs which do not include 0 , we added a ' $*$ ' symbol to implying a potential association between an explanatory variable and outcome. The outcomes were either: consistent in all three models (i.e., agreement across the board); consistent in two out of three models (i.e., some level of consistency); or inconsistent (i.e., the strength of the parameters and the coverage of the CIs were very different from one another.

Table 1. Sensitivity analysis results for three BSEMs with alternative priors

\begin{tabular}{|l|l|l|l|}
\hline & Low-level compliance & $\begin{array}{l}\text { Street-specific } \\
\text { compliance }\end{array}$ & High-level compliance \\
\hline Personal morality & $\begin{array}{l}\text { Consistent in all three } \\
\text { models * }\end{array}$ & $\begin{array}{l}\text { Consistent in all three } \\
\text { models * }\end{array}$ & $\begin{array}{l}\text { Consistent in all three } \\
\text { models * }\end{array}$ \\
\hline Risk of sanction & $\begin{array}{l}\text { Consistent in all three } \\
\text { models }\end{array}$ & $\begin{array}{l}\text { Consistent in two out } \\
\text { of three models * }\end{array}$ & $\begin{array}{l}\text { Consistent in all three } \\
\text { models }\end{array}$ \\
\hline Legitimacy & Inconsistent & $\begin{array}{l}\text { Inconsistent } \\
\text { models * }\end{array}$ \\
\hline Effectiveness & $\begin{array}{l}\text { Consistent in all three } \\
\text { models }\end{array}$ & $\begin{array}{l}\text { Consistent in all three } \\
\text { models }\end{array}$ & $\begin{array}{l}\text { Consistent in two out } \\
\text { of three models * }\end{array}$ \\
\hline Procedural Justice & $\begin{array}{l}\text { Consistent in all three } \\
\text { models }\end{array}$ & $\begin{array}{l}\text { Consistent in all three } \\
\text { models }\end{array}$ & $\begin{array}{l}\text { Consistent in all three } \\
\text { models }\end{array}$ \\
\hline
\end{tabular}

To summarize Table 1, the emerging results from the three models agreed that personal morality had a strong partial association with the different types of compliance, and that procedural justice was unrelated to them. In addition, legitimacy was also consistently associated with high-level compliance, if only weakly, and showed an inconsistent picture with regards to the other two types of compliance. In two out of three models, risk of sanction showed a positive partial association with street-specific compliance but was otherwise consistently unrelated to the other two types of compliance. In two out of the three BSEMs, effectiveness had a weak positive partial association with high-level compliance, and consistently no association with the other two types of compliance.

We used principal component analysis to derive the component scores of each of the measured constructs. We entered these component scores into the BSEM for further analysis. Due to the limited sample size, we only added age as a control variable. All analyses were carried out using the $\mathrm{R}$ and JAGS statistical programs with 10,000 burn in and 100,000 MCMC specified.

\section{Results}

Table 2. Bayesian SEM with informative priors using formative measures, the square bracket straddle credible intervals, all variables were controlled for age

\begin{tabular}{|l|l|l|l|}
\hline & $\begin{array}{l}\text { Low-level } \\
\text { compliance }\end{array}$ & $\begin{array}{l}\text { Street-specific } \\
\text { compliance }\end{array}$ & $\begin{array}{l}\text { High-level } \\
\text { compliance }\end{array}$ \\
\hline Personal morality & 0.63 & 0.59 & 0.67 \\
& {$[0.52,0.75]$} & {$[0.45,0.74]$} & {$[0.57,0.78]$} \\
\hline Risk of sanction & 0.01 & 0.15 & 0.06 \\
& {$[-0.14,0.15]$} & {$[0.01,0.31]$} & {$[-0.03,0.16]$} \\
\hline Legitimacy & 0.12 & 0.14 & 0.17 \\
& {$[-0.02,0.28]$} & {$[0.03,0.25]$} & {$[0.03,0.33]$} \\
\hline
\end{tabular}




\begin{tabular}{|l|l|l|l|}
\hline Effectiveness & 0.09 & 0.05 & 0.13 \\
& {$[-0.12,0.30]$} & {$[-0.10,0.21]$} & {$[0.02,0.25]$} \\
\hline Procedural Justice & 0.06 & -0.07 & 0.08 \\
& {$[-0.15,0.28]$} & {$[-0.43,0.268]$} & {$[-0.11,0.27]$} \\
\hline
\end{tabular}

The results from the BSEM analysis found the strongest partial association between either form of compliance and the corresponding measures of personal morality (Table 2). The effect sizes were large with the weakest association for street-specific compliance $(\beta=0.587, \mathrm{CI}=0.445-0.737)$, followed by low-level compliance $(\beta=0.632, C I=0.516-0.754)$ and high-level compliance $(\beta=0.672, C I=0.574$ 0.776 ). This was the only estimate that had a consistently strong correlation across the three models.

Police legitimacy was the second estimate which showed a consistently weak association across the models. Legitimacy had the weakest partial association with low-level compliance, where the credible intervals also included zero $(\beta=0.124, \mathrm{CI}=-0.024-0.281)$, whilst street-specific $(\beta=0.136, \mathrm{CI}=0.032$ $0.248)$ and high-level $(\beta=0.174, \mathrm{CI}=0.031-0.329)$ compliance had slightly higher effect sizes and their CIs did not include zero. Not considering whether the results indicate a 'significant' association, these estimates were fairly similar across all models, implying a weak association between legitimacy and compliance.

There were two other results that are worth highlighting from Table 2. Risk of sanction exhibited a weak association with street-level compliance $(\beta=0.154, \mathrm{CI}=0.012-0.308)$ and police effectiveness a similarly weak association with high-level compliance $(\beta=0.133, \mathrm{CI}=0.019-0.253)$. The rest of the results were not meaningfully different from zero, indicating no association with either form of compliance.

Table 3. Bayesian SEM with informative priors using formative measures, the square bracket straddle credible intervals, all variables were controlled for age

\begin{tabular}{|l|l|l|l|l|l|l|l|}
\hline & $\begin{array}{l}\text { Personal } \\
\text { morality } \\
\text { (low- } \\
\text { level) }\end{array}$ & $\begin{array}{l}\text { Risk of } \\
\text { sanction } \\
\text { (low } \\
\text { level) }\end{array}$ & $\begin{array}{l}\text { Personal } \\
\text { morality } \\
\text { (street- } \\
\text { specific) }\end{array}$ & $\begin{array}{l}\text { Risk of } \\
\text { sanction } \\
\text { (street- } \\
\text { specific) }\end{array}$ & $\begin{array}{l}\text { Personal } \\
\text { morality } \\
\text { (high- } \\
\text { level) }\end{array}$ & $\begin{array}{l}\text { Risk of } \\
\text { sanction } \\
\text { (high } \\
\text { level) }\end{array}$ & Legitimacy \\
\hline Police & 0.17 & 0.18 & 0.16 & 0.16 & 0.209 & 0.127 & 0.456 \\
effectiveness & {$[0.01$,} & {$[-0.01$,} & {$[0.03$,} & {$[-0.02$,} & {$[0.015$,} & {$[-0.076$,} & {$[0.318$,} \\
& $0.33]$ & $0.38]$ & $0.31]$ & $0.34]$ & $0.411]$ & $0.328]$ & $0.601]$ \\
\hline Procedural & 0.15 & 0.06 & 0.10 & 0.11 & 0.14 & 0.11 & 0.58 \\
justice & {$[-0.11$,} & {$[-0.20$,} & {$[-0.19$,} & {$[-0.10$,} & {$[-0.13$,} & {$[-0.18$,} & {$[0.36, .81]$} \\
\hline
\end{tabular}

Table 3 includes the results for the rest of the BSEM models. In all three models, police effectiveness was found to have a weak partial association with the corresponding form of personal morality (lowlevel: $\beta=0.168, C I=0.011-0.332$; street-specific: $\beta=0.163, C I=0.031-0.309$; high-level: $\beta=0.209$, $\mathrm{CI}=0.015-0.411)$. Police effectiveness was also associated with police legitimacy $(\beta=0.456, \mathrm{CI}=0.318$ $0.601)$ but procedural justice had a slightly stronger association $(\beta=0.579, \mathrm{CI}=0.356-0.810)$. The perceived risk of sanction appeared to be unrelated to either police effectiveness of procedural justice. 